\title{
Development of Wearable System to Help Preventing the Spread of Covid-19 in Public Indoor Area
}

\author{
Annisa Istiqomah Arrahmah ${ }^{1}$ \\ School of Computer Science \\ Bina Nusantara University Bandung Campus \\ Jakarta Indonesia 11480
}

\author{
Surya Ramadhan ${ }^{2}$ \\ School of Electrical Engineering and Informatics \\ Institut Teknologi Bandung \\ Bandung, Indonesia
}

\begin{abstract}
Smart wearables as a part of the Internet of Things nowadays gaining confidence in our daily lives because of its accessibility and simplicity. Today, with the outbreak of Coronavirus around the world, a smart wearable device can become another solution to help slowing the virus spreading by ensuring public health and social measures. In this paper, a system consisting of distance detector and touchless door access is proposed to help the personal, physical and social distancing measures practice in a public indoor area. A BLE positioning method based on RSSI localization is used to ensure the physical distancing around the user. WPA2 and MAC address-based authentication for the touchless door access is used to restrict and trace the visitor of the indoor area. The system is implemented in ESP microcontroller. A proof of concept is conducted to see if the functionality of the system already satisfied the public health and social measures practice. The results show that only registered devices can give a signal to open the door and the device can guarantee the physical distance around the user with $4.51 \%$ error in indoor area.
\end{abstract}

Keywords-Wearable device; healthcare system; COVID-19; door-lock system; radio signal strength indicator (RSSI)

\section{INTRODUCTION}

In the past year, a massive spread of respiratory disease called COVID-19 caused by a coronavirus family has changed the human interaction with the surrounding environment [1]. Experts also suggest that the world should prepare for the inevitability of COVID-19 becoming an endemic [2]. Based on [3] issued by the World Health Organization, there are two ways that COVID-19 can spread between humans. When a sick person coughs, sneezes or breathes, a droplet that contains the virus is released. These droplets mostly fall into the nearby surface of an object such as a desk, telephone or even a door knob. A healthy person could be infected with COVID-19 by touching these contaminated surfaces and then touch their face. If the health person standing near the infected person within 1 meter, they could catch COVID-19 by inhaling these droplets. Following the information, in document [4] WHO also gives guidance strategies to help reducing the spread of COVID-19 especially in the public area in the form of public health and social measures. These measures include physical and social distancing measures to prevent transmission between infected persons to those who are not infected and personal measures to limit person to person spread and reduce contamination on frequently touched surfaces. These measures can be in the form of physical distancing, frequent hand hygiene, avoiding crowded space, contact tracing and limiting surface contact as minimum as possible. In [5], research about the impact of physical distance measures on the transmission of COVID-19 in the UK is conducted. The research is done by comparing contact patterns during pandemic and non-pandemic situations. In the result, the researchers state that physical distance measures give a $74 \%$ reduction in average daily contact that led to a substantial impact in reducing the cases in the incoming week. Another research [6] is performed in several countries in Europe and gave similar results. As an example, the researchers state that in Germany, physical distance measures give $49 \%$ reduction, while in Italy they give $83 \%$ reduction.

In Indonesia, the personal, physical and social distance measures are established as a health protocol called 3M. Several studies shows that the health protocol awareness in Indonesia is still lower than 50\% [7]-[9]. In contrast, the indoor public area such as workplace, education place and marketplace are gradually starting to allow people in. Thus, an additional system to support the health protocol enforcement is needed. A wearable system is a suitable system that can be implemented since it enables fast data and information flow, particularly relevant for the rapid infectious character of COVID-19 virus [10].

In this paper, a wearable system is proposed to help ensuring the personal, physical and social distancing measures especially in restricted public indoor areas. The system consists of two main functions; distance detector and touchless door access. The distance detector is used to ensure the physical distance in the indoor area based on the minimum distance suggested by WHO. The touchless door access has two purposes. First, limiting the surface contact area in the door handles as it is one of the most high-touch surfaces with $33 \%$ virus RNA positive rate traces [11], [12]. Second, to limit the access of the area as only people that wear the device and registered can enter the area, making it easier for contact tracing. This wearable system is implemented in embedded systems ESP microcontroller. For the distance detector module, this system adopts Bluetooth positioning method using RSSI localization. Thus, a safe social distance can be maintained around the user. The touchless door access utilizes the Wifi communication mechanism to open the gate automatically. By using WPA2 and MAC-based authentication processes, only authorized users that wear the device are allowed to enter the area. 
Current system to ensure the personal, physical and social distancing is mostly done by giving regulation without any tools to strictly ensure the implementation of the measures. For example, the newest regulation in Indonesia utilizes a mobile application to track the user's indoor area visit history [13] by sharing the user's location based on GPS to the server system while the user entering the area. But this system cannot confirm the physical distancing measures among the visitors inside the area and no minimal limitations of visitors at a certain time. The proposed system encounters the shortage of the aforementioned system to ensure all measures are implemented. By using wearables system, a strict regulation without relying on user's phone can be established and future data collection for tracking and tracing can be carried out.

This paper is divided into the following sections. Section I presents the background of the research and the previous work related to this paper. Section II explains about previous research related to this research. Section III discusses basic theories used in this research. Section IV explains the proposed design. Section $\mathrm{V}$ shows the research implementation and testing result. Section VI concludes the research done in this paper, respectively.

\section{RELATED WORK}

In [10], authors suggest several approaches and principles in wearables systems and sensor recommendation used for symptom tracking and contact tracing. Mostly the suggestion is still in the initiative scale and there is no further development in specific one system to help the social and physical measures enforcement. In this research, as the wearable system consists of two main functions; touchless door access and distance detector, research and technology selection related to the mentioned functions are considered.

\section{A. Distance Detector}

There are different methods that have been used to detect, and measure the distance of objects such as Bluetooth, Wifi, or ultrasound [14]. Bluetooth and Wifi technology measure the distance using a signal strength modeling while the ultrasound using lateration. In this system, human detection should be done in 360 degrees around the user. If there are people who are too close to the user, then the system will give a warning. Based on article [15], the safe distance between humans for social distance is about 1.5 meters. By using the distance detector, the user can perform the social distancing appropriately especially in the indoor area. In [16]-[18] a distance sensing and detector system is implemented in embedded system using ultrasonic sensor. Yet, this sensor has limitations for the aforementioned condition of the system. Ultrasonic sensor has a limited angle detection range with a maximum $15^{\circ}$ degree measuring angle. By using one sensor, the detected object is limited to only one direction. A signal strength method such as Bluetooth based or Wifi based is a decent method for the COVID-19 distance detector because they sense the object within the radius range. Another technology that can be used is BLE (Bluetooth Low Energy), a low power version of Bluetooth [19]. The comparison between Bluetooth, Wifi and BLE technologies can be seen in Table I.
TABLE I. BLUETOOTH Vs Wifi Module TeChNOLOGIES

\begin{tabular}{|c|c|c|c|}
\hline \multirow{2}{*}{ Comparison } & \multicolumn{3}{|c|}{ SPM Method } \\
\hline & Bluetooth & Wifi & $B L E$ \\
\hline Frequency & $2.4 \mathrm{GHz}$ & $2.4,3,5 \mathrm{GHz}$ & $2.4 \mathrm{GHz}$ \\
\hline Chip Cost & Low & High & Low \\
\hline Bandwidth & 1-3 Mbps & $11 \mathrm{Mbps}$ & 1-2 Mbps \\
\hline Security & Less secure & Secure & Less secure \\
\hline $\begin{array}{l}\text { Power Consumption } \\
\text { (Active mode) }\end{array}$ & $\sim 600 \mathrm{~mW}$ & $\sim 950 \mathrm{~mW}$ & $3 \mathrm{~mW}$ \\
\hline
\end{tabular}

In COVID-19 distance detector, the device's purpose is to detect people around the user in a fairly long period of time. Thus, the device operation time or the battery power is more considered than the positioning precision. Then, BLE is the best option method for this scenario because the system is performed in a low cost, low bandwidth and low security risk tolerance.

\section{B. Touchless Door Access}

Touchless door access adopts the mechanism of smart door lock system with the purpose to unlock the door automatically. There are several researches that have been conducted in this area. In [20]-[22], the door lock system utilizes Wifi and Bluetooth to communicate with the door lock mechanism. Authentication process is done by using a password in a mobile application. In [19], an OTP insertion is added to increase the level of security. In [23], [24], a radio signal such as Wifi and Bluetooth is used for the authentication process. In [22] they also used MAC- based authentication while in [23] they used password-based authentication. All of the aforementioned research is implemented in a mobile phone and uses a mobile application for authorization.

In this system, the touchless door access adapts the Wifi based authentication. This system is implemented in ESP embedded system. For additional level of security, MAC based authentication is added to the system. Thus, two-factor authentication is applied to ensure the genuineness of the device.

\section{BASIC THEORIES}

In this section, basic theories related to the proposed design are explained.

\section{A. RSSI (Radio Signal Strength Indicator)}

Received Signal Strength Indicator readings is a method to measure a distance between two Bluetooth devices. Radio Signal Strength using Bluetooth positioning has been studied in several studies[25]-[27]. This research adapts the RSSI reading method proposed in [28]. The mentioned method uses the newest Bluetooth standard mostly used in today's electronic devices. The distance between two radio devices is calculated using the RSSI and a proper radio propagation model is used. The RSSI is estimated using equation (1).

$R S S I=-\left(10 n \log _{10} d+A\right)$

$\mathrm{A}$ and $\mathrm{n}$ are RF parameters for describing the network peripheral. The RF parameter A, represented by $\mathrm{dBm}$, defines 
the absolute energy emitted by the transmitter at 1 meter range. In other words, $\mathrm{A}$ is the RSSI reading at 1 meter from the transmitter. Parameter $\mathrm{n}$ represents the transmission constant and relevant with the signal transmission constant. Distance $d$ is the distance between receiver and transmitter node.

The value of RF parameter $\mathrm{A}$ and $\mathrm{n}$ are calculated by using RSSI values and distance $\mathrm{d}$ read by the sensors. The RSSI value is the received power of the reference node while the $d$ is the distance between two reference nodes. The transmitter constant $\mathrm{n}$ between two reference nodes is estimated using equation (2).

$n_{i}=\left(\frac{R S S I-A}{10 \log _{10} d_{i}}\right)$

Another way to calculate the RF parameters is using a regression stated in [29]. First, the dataset of RSSI relevant to the distance $d$ are collected. Then equation (1) is transformed into equation (3). Parameter $\mathrm{A}$ and $\mathrm{n}$ are obtained experimentally based on the collected dataset.

$\mathrm{y}=-10 n \log _{10} x-A$

\section{PROPOSED DESIGN}

\section{A. Sytem Architecture}

In this research a wearable system to ensure the personal, physical and social distancing measures is proposed. The use case scenario of the system can be seen in Fig. 1. Based on the figure, while a person wants to enter the restricted indoor area, a prescreening and registration process should be done for data tracing. After that, they receive the registered device to be worn on their body. Thus, only a person who owns and wears the device can enter the area. Inside the area, they should maintain the distance with the other by the help of the device. If the user stands too near with another, then the device gives a warning. The wearable device uses ESP32[30] embedded platform. The schematic of the device can be seen in Fig. 2. The device consists of a switch button circuit, the microcontroller, a battery and a buzz circuit. The switch button is pressed by the user while they want to enter the building/area. The buzz circuit is used as a warning sign to the user if they violate the physical distancing rules.

\section{B. Covid-19 Distance Detector}

The distance detector utilizes the Bluetooth Low Energy (BLE) module embedded in ESP32 device. BLE is chosen for the distance detector based on Section 2. The distance detector system needs at least two devices to communicate between the BLE client and server and works as a distance detector. While the user is entering the area, the device will turn on its BLE client and server mode alternately in an infinite loop until another higher level of interrupt event occurs. The flowchart between two devices can be seen in Fig. 3 .

During the client mode, the device acts as an observer and during the server mode the device acts as a broadcaster. While the BLE is set as a broadcaster, the device broadcasts its advertising data. Whereas the BLE is set as an observer, the device scans all available devices around by capturing the advertising data issued by the BLE broadcaster. During this mode, the user device captures data consisting of BLE name, address, service UUID, TX power and RSSI. By using the captured RSSI information, the observer calculates the broadcaster origin distance using Eq. 4. If the distance of the broadcaster is less than the allowed distance, then the microcontroller gives a signal to the buzzer and the buzzer produces a warning sound.
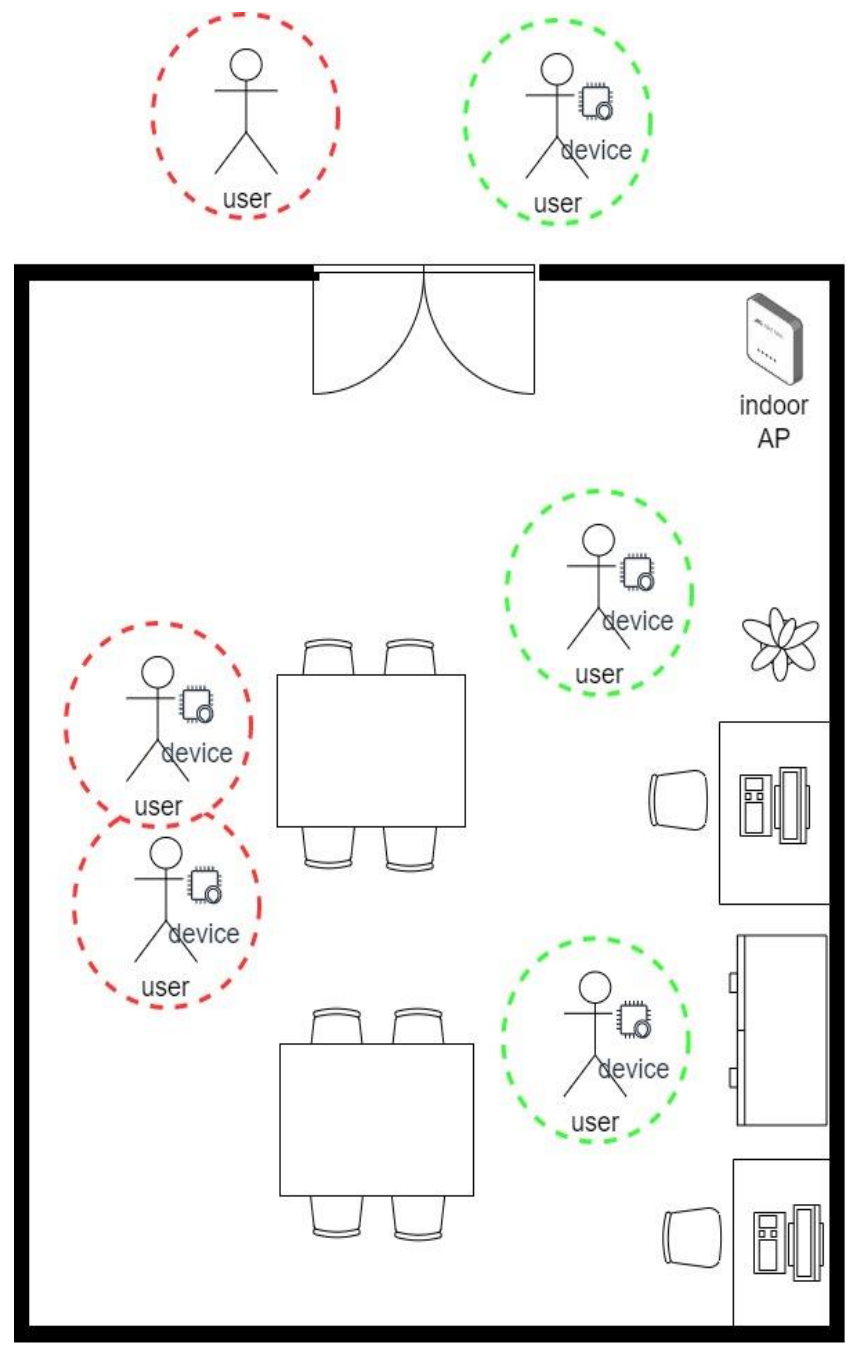

Fig. 1. Example of Physical Measures System Scenario in the Indoor Area

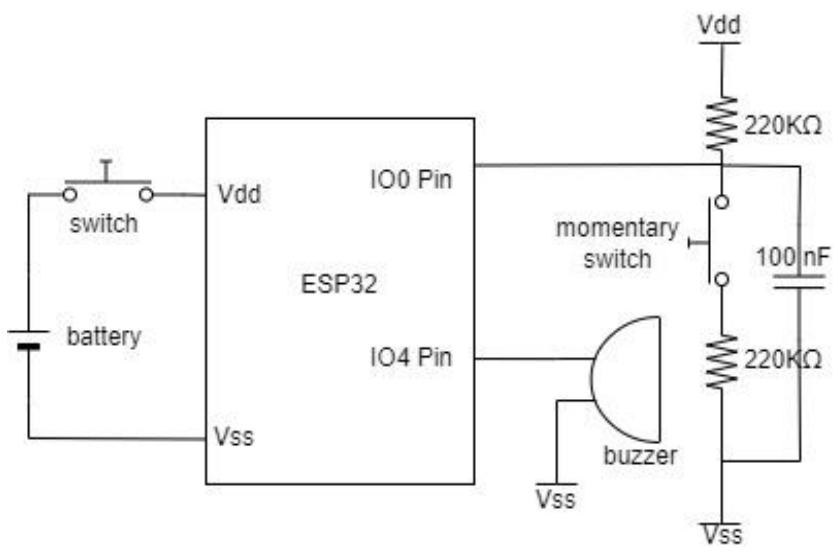

Fig. 2. Schematic of the Wearable Device. 


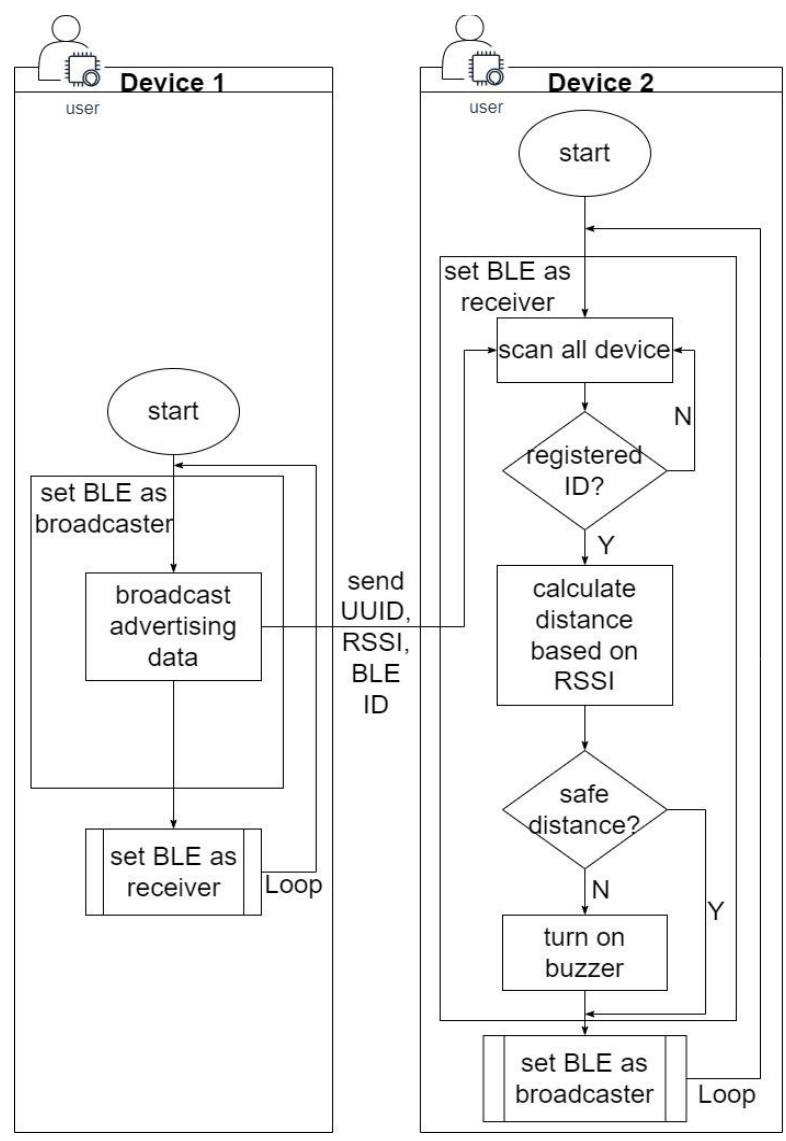

Fig. 3. Flowchart of the Distance Detector.

\section{Touchless Door Access Module}

The touchless door access mechanism utilizes two-way factor authentication for the authorized users' authentication. The detailed authentication processes can be seen in Fig. 4. An ESP8266[31] near the front door acts as a server (AP) while an ESP32 in the wearable device worn by the user acts as a client. The door is opened if a client device requests a connection to the Wifi AP device. A request is made by the user by pressing the switch button in the device. After the switch button is pressed, the WPA2 client mode is activated and the device requests an authentication to the AP device. If an authentication process is successful, the device requests an association to the AP by giving MAC address information. Then, the AP verifies the client's MAC address against a locally configured list of allowed addresses. If the MAC address matches, a response is sent to the device and the AP generates a signal to the door lock mechanic to open the door. The door-lock mechanism is not the scope of this paper.

The flowchart of the client device and the AP device can be seen in Fig. 5. In the client device, BLE is run as a default. The Wifi client is activated and the BLE is turned off if a GPIO interrupt occurs from a button press. Thus, a flag is raised to inform the loop function that a button has been pressed. After the flag is cleared, the Wifi client is turned on and an authentication process is performed. In the AP device, the device always turns on its AP mode, scans clients, performs authentication processes and sends a signal to the door-lock mechanism.

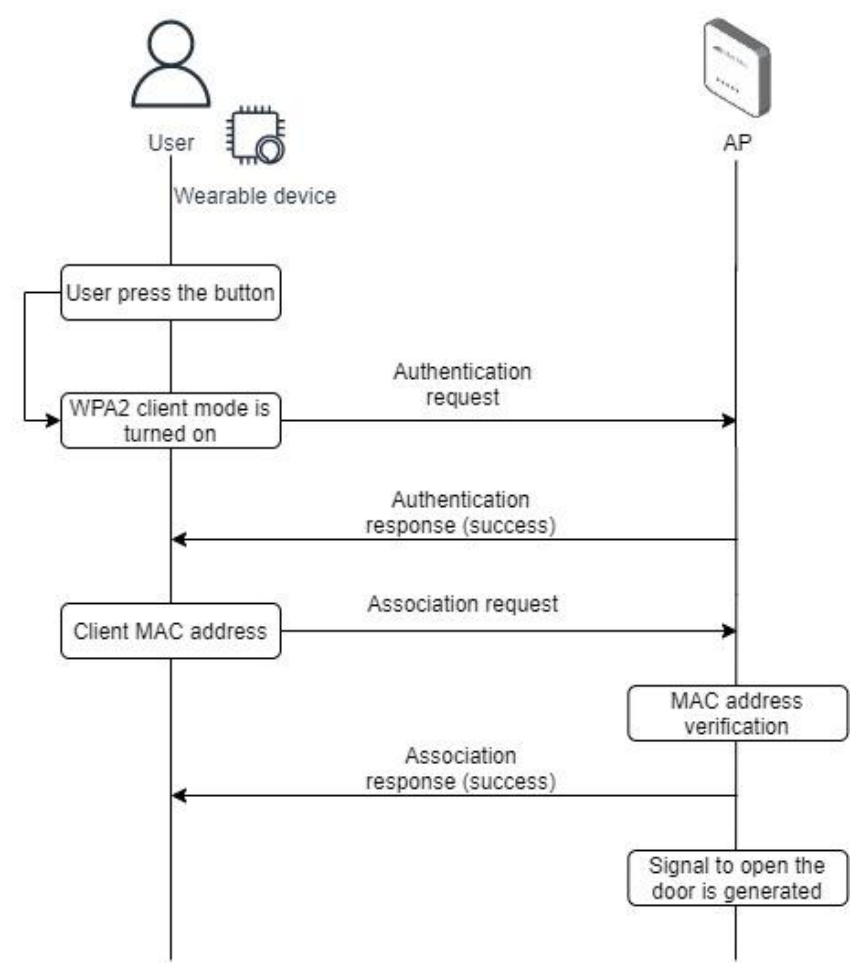

Fig. 4. Authentication Process.

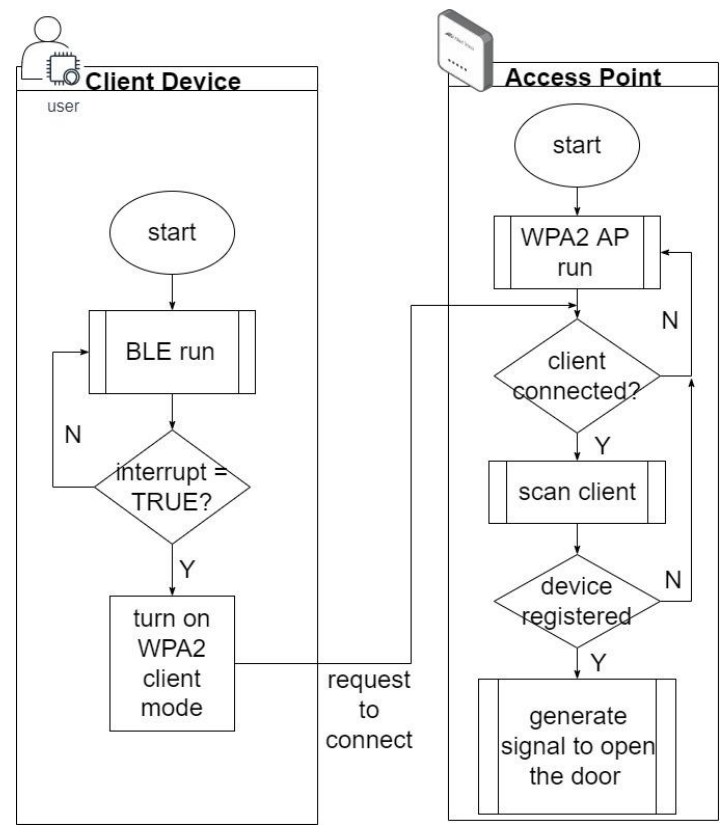

Fig. 5. AP and Client Device Flowchart.

\section{RESUlt AND DISCUSSION}

\section{A. System Implementation}

The implementation of the device is done in a controlled experiment environment. The prototype of the wearable device is shown in Fig. 6. The components of the device are explained in Table II. For the power input, a rechargeable Lithium-ion battery is used. For the output, an active buzzer is used to give a sound alarm if another device is detected less than 1.5 meters away. 


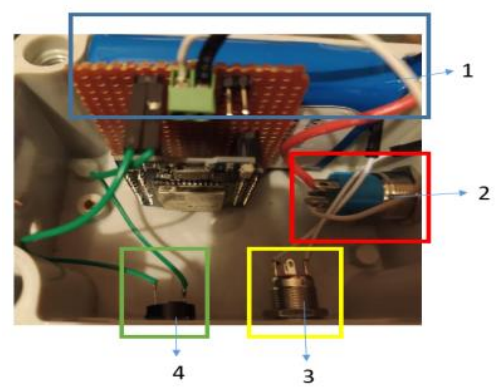

Fig. 6. Implementation of the Smart Key.

TABLE II. FIGURE 5 EXPLANATION

\begin{tabular}{|l|l|l|}
\hline No. & Box Color & Component Explanation \\
\hline 1 & Blue & Lithium-ion Battery \\
\hline 2 & Red & Power switch \\
\hline 3 & Yellow & Wifi switch button \\
\hline 4 & Green & Buzzer \\
\hline
\end{tabular}

TABLE III. FUNCTIONALITY TEST

\begin{tabular}{|l|l|l|}
\hline \multirow{2}{*}{ Function } & Result \\
\cline { 2 - 3 } Distance Detector & Trigger & Output \\
\hline & Less than 1.5 meters & The buzzer ring \\
\cline { 2 - 3 } Touchless door access & More than 1.5 meters & $\begin{array}{l}\text { The buzzer does } \\
\text { not ring }\end{array}$ \\
\hline & $\begin{array}{l}\text { Registered Client device } \\
\text { near the AP device }\end{array}$ & $\begin{array}{l}\text { A signal to open } \\
\text { the door is } \\
\text { generated }\end{array}$ \\
\cline { 2 - 3 } & $\begin{array}{l}\text { Unregistered Client device } \\
\text { near the AP device }\end{array}$ & $\begin{array}{l}\text { A signal to open } \\
\text { the door is not } \\
\text { generated }\end{array}$ \\
\hline
\end{tabular}

The functionality test result of the system can be seen in Table III. For the distance detector, another test is done by comparing the distance result using RSSI with actual distance to obtain the device accuracy. For the touchless door access, because the mechanic of the door lock system is not the scope of this system, the output is only a signal to open or to close the door that should be interpreted by the next-door lock system mechanism.

\section{B. Distance Calculation Parameter}

Based on equation (1), the RSSI values and distance $d$ should be gathered to achieve the parameter $\mathrm{A}$ and $\mathrm{n}$ values. The RSSI and distance values are obtained at multiple defined points. The experiment is done inside a room with dimension $5.4 \mathrm{~m} \times 2.7 \mathrm{~m}$ and the beacon is placed 0.5 meters above the ground. The RSSI are gathered 25 times at 14 specified positions. For each position, the mean value of the RSSI samples is calculated. By using this dataset of average RSSI value, a logarithmic function by using a fitting curve is made. The obtained function and the curve model can be seen in Eq. 4 and Fig. 7, respectively.

$R S S I=-\left(19.38 \log _{10} d-48.86\right)$

\section{Distance Detector Accuracy}

The distance detector works by giving an alarm if another device is near the user device. Based on Section 2, the minimum distance for social distancing is 1.5 meters. The testing process is conducted by comparing the distance value computed from Eq. 4 with the actual distance. The test is taken on the fixed distance point to determine the accuracy. The accuracy of the distance detector system is determined by using measurement performance tools. For each distance point, the output distance samples for one minute are gathered. For data accuracy, the modus (mode) data of the samples are used. Based on Table IV, the error value of the output is declining while the distance is increasing. Oppositely, the data variance is increasing with the distance. The error value in the distance for social distancing $(1.5 \mathrm{~m})$ is reasonable enough, i.e. $4.51 \%$ (average) or $0.39 \%$ (modus). The performance curve model can be seen in Fig. 8. Based on the figure, the higher the distance, the system becomes less precise.

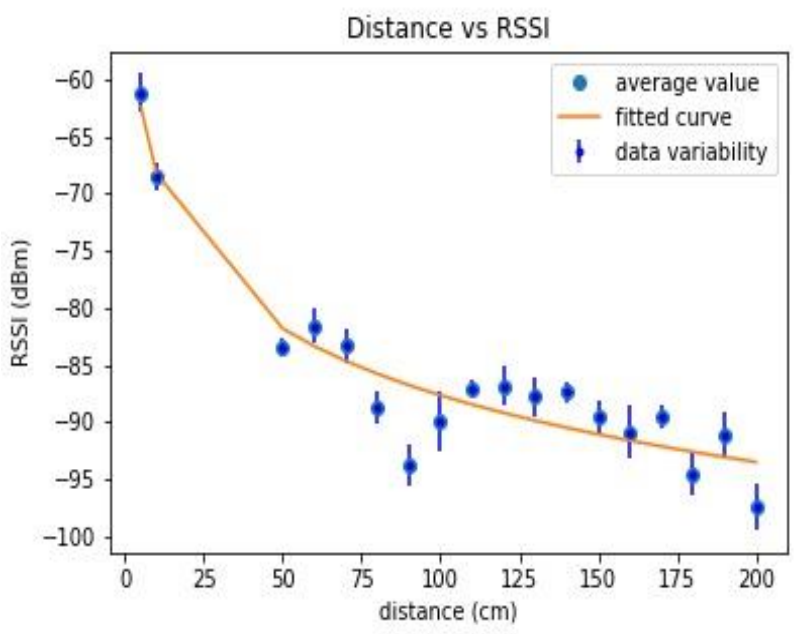

Fig. 7. Distance vs RSSI.

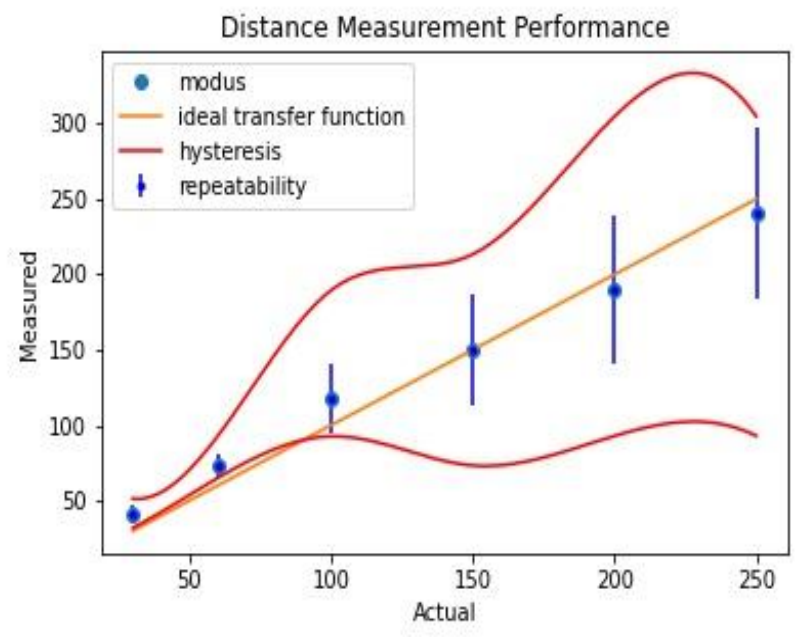

Fig. 8. Distance Measurement Performance. 
TABLE IV. Distance Detector Performance

\begin{tabular}{|l|l|l|l|l|}
\hline $\begin{array}{l}\text { Actual } \\
\text { distance } \\
(\mathbf{c m})\end{array}$ & \multicolumn{4}{|l|}{ Measured distance $(\mathbf{c m})$} \\
\cline { 2 - 5 } & Modus & Error $(\%)$ & Average & Error $(\%)$ \\
\hline 30 & 40.44 & 34.8 & 39.62 & 32.07 \\
\hline 60 & 73.25 & 22.08 & 74.69 & 24.48 \\
\hline 100 & 117.82 & 17.82 & 129.39 & 29.39 \\
\hline 150 & 149.42 & 0.39 & 143.23 & 4.51 \\
\hline 200 & 189.5 & 5.25 & 184.19 & 7.9 \\
\hline 250 & 240.33 & 3.87 & 214.03 & 1 \\
\hline
\end{tabular}

\section{Touchless Door Access}

The implementation of the two-way authentication of the touchless door access can be seen in Fig. 9. After the authentication using WPA2 successes, a MAC address verification is performed. Fig. 9(b) shows the result that the client device with E0:1F:88:66:4E:2E MAC address has not been registered to the AP device. Thus, the system generates output signal to prevent the door-lock system opening the door. Fig. 9(a) shows that the MAC address' client device is registered in the AP device and matches with the lookup table. Thus, when the client device approaches the AP device and a request is made, an output signal to open the door is generated.

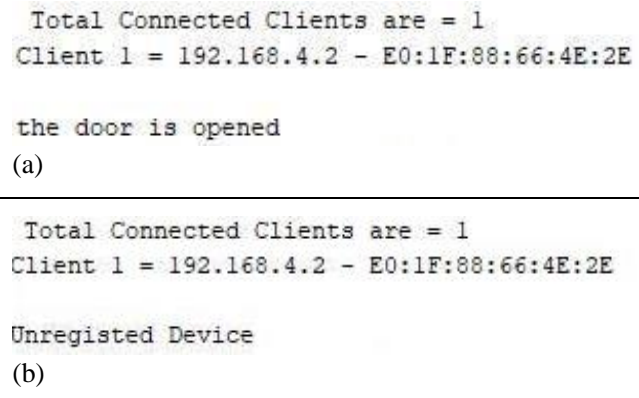

Fig. 9. (a) Registered Client (b) Unregistered Client.

\section{CONCLUSION}

In this paper, a prototype of a wearable system to help public health and social measures practice in public indoor areas is proposed. The system consists of two main functions; distance detector for physical distancing measures and touchless door access for personal measures. The system is implemented in ESP32 microcontroller. The system uses MAC based and WPA2 based authentication for the touchless door access application and BLE positioning based on RSSI localization for the distance detector. The functionality test has been conducted and the system successfully generates the desired output. The touchless door access shows that only a device with a registered MAC address can access the AP and generates a signal to open the door. The BLE based distance detector module has a reasonable performance for the social distancing parameter, i.e., $1.5 \mathrm{~m}$. It has an average $4.51 \%$ error around 1.5 meters with $\sigma=6.16-57.2$ around the tested distance.

The performance of the system still focuses on the theoretic and technical result; thus, overall evaluation of the system as digital contact tracing should be done in a practical scope. For the future works, the data collected from the system can be performed automatically by utilizing Internet of Things. The collected data can be processed by epidemiological for tracking, tracing and modeling purposes.

\section{REFERENCES}

[1] H. A. Rothan and S. N. Byrareddy, "The epidemiology and pathogenesis of coronavirus disease (COVID-19) outbreak," J. Autoimmun., vol. 109, no. February, p. 102433, 2020, doi: 10.1016/j.jaut.2020.102433.

[2] P. Hunter, “ The spread of the COVID - 19 coronavirus ," EMBO Rep., vol. 21, no. 4, pp. 1-3, 2020, doi: 10.15252/embr.202050334.

[3] WHO, "Getting your workplace ready for COVID-19," World Heal. Organ., no. March, pp. 1-8, 2020, [Online]. Available: www.WHO.int.\%0Awww.WHO.int\%0Awww.WHO.int.

[4] WHO, Overview of public health and social measures in the context of COVID-19, no. May. 2020, pp. 1-8.

[5] C. I. Jarvis et al., "Quantifying the impact of physical distance measures on the transmission of COVID-19 in the UK," pp. 1-10, 2020.

[6] E. Del Fava et al., "The differential impact of physical distancing strategies on social contacts relevant for the spread of COVID-19," medRxiv, 2020, doi: 10.1101/2020.05.15.20102657.

[7] F. Prasetya and I. Yunawati, "Public Perception of Covid-19: Implementation of Health Protocols in West Muna District Persepsi Masyarakat Tentang Covid-19: Penerapan Protokol Kesehatan di Kabupaten Muna," vol. 2, no. 1, pp. 32-41, 2021, doi: 10.24252/diversity.v2i1.21391.

[8] S. Artama, Rif'atunnisa, and B. M. L, "Kepatuhan Remaja Dalam Penerapan Protokol Kesehatan Pencegahan Covid-19 Di Lingkungan Sangingloe Kecamatan Tamalatea Kabupaten Jeneponto," J. Ilm. Kesehat. Pencerah, vol. 10, no. 1, pp. 65-72, 2021, [Online]. Available: https://stikesmu-sidrap.e-journal.id/JIKP/article/view/241.

[9] F. D. A. Pinasti, "Analisis Dampak Pandemi Corona Virus Terhadap Tingkat Kesadaran Masyarakat dalam Penerapan Protokol Kesehatan," Wellness Heal. Mag., vol. 2, no. 2, pp. 237-249, 2020, doi: 10.30604/well.022.82000107.

[10] O. Amft, L. Lopera, P. Lukowicz, S. Bian, and P. Burggraf, "Wearables to Fight COVID-19: From Symptom Tracking to Contact Tracing," IEEE Pervasive Comput., vol. 19, no. 4, pp. 53-60, 2020, doi: 10.1109/MPRV.2020.3021321.

[11] K. Razzini et al., "Science of the Total Environment SARS-CoV-2 RNA detection in the air and on surfaces in the COVID-19 ward of a hospital in Milan , Italy," Sci. Total Environ., vol. 742, p. 140540, 2020, doi: 10.1016/j.scitotenv.2020.140540.

[12] J. E. Powers, M. L. Nadimpalli, T. R. Julian, and A. J. Pickering, Longitudinal monitoring of SARS-CoV-2 RNA on high touch surfaces in a community setting. pp. 1-17.

[13] A. Fadli, "M ENGENAL C OVID -19 DAN C EGAH $P$ ENYEBARANNYA D ENGAN ' $P$ EDULI L INDUNGI' A PLIKASI B ERBASIS A NDORID," no. April, 2020.

[14] L. Batistic and M. Tomic, "Overview of indoor positioning system technologies," 2018 41st Int. Conv. Inf. Commun. Technol. Electron. Microelectron. MIPRO 2018 - Proc., pp. 473-478, 2018, doi: 10.23919/MIPRO.2018.8400090.

[15] N. Williams, "Social Distancing in the Covid-19 Pandemic," Occup. Med. (Chic. Ill)., vol. 70, no. 5, p. 305, 2020, doi: 10.1093/occmed/kqaa072.

[16] N. Anju Latha, B. Rama Murthy, and K. B. Kumar, "Distance Sensing with Ultrasonic Sensor and Arduino," Int. J. Adv. Res. Ideas Innov. Technol., vol. 2, no. 5, pp. 1-5, 2016.

[17] N. Dey, A. Paul, P. Ghosh, C. Mukherjee, R. De, and S. Dey, "Ultrasonic Sensor Based Smart Blind Stick," Proc. 2018 Int. Conf. Curr. Trends Towar. Converging Technol. ICCTCT 2018, pp. 1-4, 2018, doi: 10.1109/ICCTCT.2018.8551067.

[18] L. Koval, J. Vaňuš, and P. Bilík, "Distance Measuring by Ultrasonic Sensor," IFAC-PapersOnLine, vol. 49, no. 25, pp. 153-158, 2016, doi: 10.1016/j.ifacol.2016.12.026. 
[19] A. Mackey, P. Spachos, L. Song, and K. N. Plataniotis, "Improving BLE Beacon Proximity Estimation Accuracy Through Bayesian Filtering," IEEE Internet Things J., vol. 7, no. 4, pp. 3160-3169, 2020, doi: 10.1109/JIOT.2020.2965583.

[20] P. Tilala, A. K. Roy, and M. L. Das, "Home access control through a smart digital locking-unlocking system," IEEE Reg. 10 Annu. Int. Conf. Proceedings/TENCON, vol. 2017-Decem, pp. 1409-1414, 2017, doi: 10.1109/TENCON.2017.8228079.

[21] T. Adiono, S. Fuada, S. F. Anindya, I. G. Purwanda, and M. Y. Fathany, "IoT-enabled door lock system," Int. J. Adv. Comput. Sci. Appl., vol. 10, no. 5, pp. 445-449, 2019, doi: 10.14569/ijacsa.2019.0100556.

[22] A. Kassem, S. El Murr, G. Jamous, E. Saad, and M. Geagea, "A Smart Lock System Using Wifi Security," in 2019 4th International Conference on Advances in Computational Tools for Engineering Applications, ACTEA 2019, 2019, pp. 222-225.

[23] N. Hashim, N. F. A. M. Azmi, F. Idris, and N. Rahim, "Smartphone activated door lock using WiFi," ARPN J. Eng. Appl. Sci., vol. 11, no. 5, pp. 3309-3312, 2016.

[24] S. Jensen, "Proximity Door Locking," 2019.
[25] A. K. M. M. Hossain and W. S. Soh, "A comprehensive study of bluetooth signal parameters for localization," IEEE Int. Symp. Pers. Indoor Mob. Radio Commun. PIMRC, 2007, doi: 10.1109/PIMRC.2007.4394215.

[26] C. Zhou, J. Yuan, H. Liu, and J. Qiu, "Bluetooth Indoor Positioning Based on RSSI and Kalman Filter," Wirel. Pers. Commun., vol. 96, no. 3, pp. 4115-4130, 2017, doi: 10.1007/s11277-017-4371-4.

[27] H. Chen, "Bluetooth Indoor Positioning Research Based on RSSI of the Least Square Positioning Algorithm," vol. 3, no. 7, pp. 77-82, 2016.

[28] Institute of Electrical and Electronics Engineers., "2013 IEEE 10th Consumer Communications and Networking Conference (CCNC) : 1114 January 2013, Las Vegas, USA.," pp. 837-842, 2013.

[29] F. Vanheel, J. Verhaevert, E. Laermans, I. Moerman, and P. Demeester, "Automated linear regression tools improve RSSI WSN localization in multipath indoor environment. EURASIP J. Wireless Comm. and Networking 2011: 38 (2011)," EURASIP J. Wirel. Commun. Netw., pp. 1-27, 2011.

[30] Espressif, "ESP32 Series Datasheet," Espr. Syst., pp. 1-61, 2019, [Online]. Available: www.espressif.com.

[31] E. Systems, "ESP8266EX," 2020. 